\title{
O projeto de parque urbano e os riscos da exposição ao calor
}

\author{
The design of urban park and the risks of exposure to \\ heat
}

\section{Marcelo Paes de Barros \\ Marta Cristina Jesus Albuquerque Nogueira Carlo Ralph De Musis}

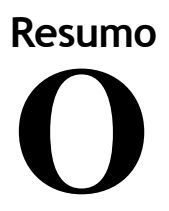

artigo trata de um estudo desenvolvido no Parque Mãe Bonifácia, grande área verde na região central de Cuiabá, MT, entre novembro de 2007 e outubro de 2008, com o objetivo de avaliar a influência das diferentes intervenções urbanísticas sobre o ambiente térmico do lugar e os possíveis impactos destas nos níveis de estresse térmico a que estão submetidos os organismos dos usuários do espaço. A investigação dos diferentes microclimas foi realizada mediante medições fixas, na praça principal do Parque, e móveis, ao longo das trilhas. A aplicação da metodologia permitiu registrar atenuações da temperatura do ar de até $3,0^{\circ} \mathrm{C}$ nas trilhas mais estreitas, onde foi preservada a vegetação do lugar, enquanto outros espaços construídos no interior do Parque apresentaram elevações máximas de até $3,2^{\circ} \mathrm{C}$, revelando a necessidade de precauções especiais para a prática de atividades físicas, especialmente na estação seca. Esses resultados sugerem que existe uma relação direta entre os padrões de ocupação do solo, topografia e características da vegetação de cada microespaço e o ambiente térmico do lugar, e que as intervenções do projeto, em alguns de seus espaços, não foram compatíveis com os rigores climáticos da região, acentuando as sensações de desconforto térmico.

Palavras-chave: Transtornos de estresse. Microclima. Área verde. Temperatura ambiente.

\section{Abstract}

This article refers to a study conducted on Mãe Bonifácia Park, a large green area of the central region of Cuiabá, MT, between November 2007 and October 2008, aiming to evaluate the influence of the urban architecture interventions on the thermal environment of the place, and to examine possible impacts of these on the heat stress level that are exposed the users organisms. Different kinds of microclimates were observed by steady measurement, placed in the main square of the Park, and by mobile measurement, along trails. The application of the methodology indicated that there were attenuations in the air temperature up to $3.0^{\circ} \mathrm{C}$ in the narrower trails, where the native vegetation was preserved. However, in the park built spaces a maximum elevation up to $3.2{ }^{\circ} \mathrm{C}$ was observed, indication the need for special care on the practice of physical activities, especially in the dry season. These results suggest that there is a direct relationship between the soil occupation standard, topography, and vegetation characteristics in each micro-space, on the thermal environment of the place. It was also possible to conclude that interventions defined by the design were not adequate for the severe climate of the region, increasing the perception of thermal discomfort.

Recebido em 10/10/2009 Aceito em 21/06/2010
Keywords: Disorders of stress. Microclimate. Green area. Environment temperature. 


\section{Introdução}

Nos últimos anos, os moradores da cidade de Cuiabá, MT, ganharam parques onde podem se exercitar. No mais popular, o Mãe Bonifácia, em horários escolhidos pelos esportistas para driblar o calor, a população se exercita, encontra amigos e descobre o prazer de levar uma vida mais saudável (ROMA, 2008).

Intervenções públicas que promovam atividades físicas, não apenas centradas nas pessoas, mas com foco também em fatores como sociais e do ambiente físico, podem ser formas de implementar políticas de saúde. Investimentos nesse sentido têm produzido impactos positivos no setor da saúde. Na cidade de Ilhabela, SP, ações de difusão dos benefícios das atividades físicas e a construção de pistas de caminhada produziram um aumento de $33 \%$ no nível de atividade física de sua população (MATSUDO et al., 2006).

A Organização Mundial da Saúde (OMS) recomenda que, dependendo do tipo e da intensidade da atividade física, pelo menos 30 minutos de atividade regular diariamente podem reduzir o risco de doenças cardiovasculares e diabetes, melhora do estado funcional de idosos, além de benefícios em relação a outros males associados à obesidade (WHO, 2006). No entanto, mesmo diretamente associada a melhorias da saúde dos praticantes, toda atividade física deve ser precedida de uma série de exames cardiológicos e clínicos, e controlada por profissionais de Educação Física, cuidados sem os quais as atividades físicas podem ser tão perigosas quanto o sedentarismo.

As condições térmicas do ambiente também constituem fator importante para a prática saudável de exercícios físicos. Em cidades tropicais, os espaços destinados ao lazer da população apresentam microclimas fortemente dependentes do projeto, levando a sensações de conforto ou desconforto térmico.

Lamberts e Xavier (2002) alertam que a prática de exercícios físicos em condições ambientais extremas de calor pode levar o indivíduo a apresentar uma queda de desempenho ao longo de sua atividade ou, ainda, a apresentar algum dano físico mais sério, debilitando seu estado geral de saúde. Estresse por calor pode ocorrer com atletas que praticam exercícios físicos nas horas mais quentes do dia e com trabalhadores expostos às mesmas situações em virtude das atividades profissionais executadas.

$\mathrm{O}$ crescente interesse pela temática tem produzido estudos relacionando as alterações do clima urbano às condições de saúde e qualidade de vida da população. $\mathrm{Na}$ Biometeorologia Urbana são conduzidos estudos sobre a influência dos microclimas em edifícios ou cidades na saúde da população (LACAZ, 1972). A Arquitetura Sustentável, na descrição de Corbella (2003), surgiu da necessidade de se criarem espaços que considerem, além das características da vida do lugar, a relação entre o espaço construído e o clima da região.

O presente trabalho teve por objetivo realizar uma análise microclimática em um parque urbano da cidade de Cuiabá. Além disso, a avaliação da influência dos diferentes usos do solo sobre o ambiente térmico do parque permitiu uma análise dos níveis de estresse térmico a que estão submetidos os usuários do parque, para subsidiar políticas públicas de melhorias em projetos de espaços destinados ao deleite da população.

\section{Métodos}

\section{Área de estudo}

Fundada a partir da exploração do ouro nos rios da região no início do século XVIII, a cidade de Cuiabá, devido a sua localização, no interior do continente, permaneceu durante muito tempo à margem do movimento capitalista realizado sobre a vida urbana. A partir das décadas de 1960 e 70 com a implementação da política federal de ocupação do centro-oeste brasileiro, a urbanização aconteceu de forma acelerada e desorganizada, principalmente por invasões de áreas periféricas.

Situada na zona intertropical do Planeta, seu clima é identificado prioritariamente pela temperatura, apresentando duas estações bem definidas, uma seca, de abril a outubro, e outra chuvosa, de novembro a março, com médias anuais entre $28{ }^{\circ} \mathrm{C}$ e $32{ }^{\circ} \mathrm{C}$. A cobertura vegetal da área urbana é constituída por remanescentes de cerrado e matas ciliares, formando um verdadeiro cinturão em torno da área urbana da Cidade.

Como forma de preservar uma área de 77 hectares de cerrado remanescente da zona urbana da cidade, lugar outrora ocupado por um quilombo, criou-se em 2000 o primeiro parque urbano do estado, o Parque Mãe Bonifácia, área de estudo deste trabalho (Figura 1). Atualmente o entorno do Parque Mãe Bonifácia, resultado, em parte, da criação dele, é uma região de grande expansão de empreendimentos imobiliários. 


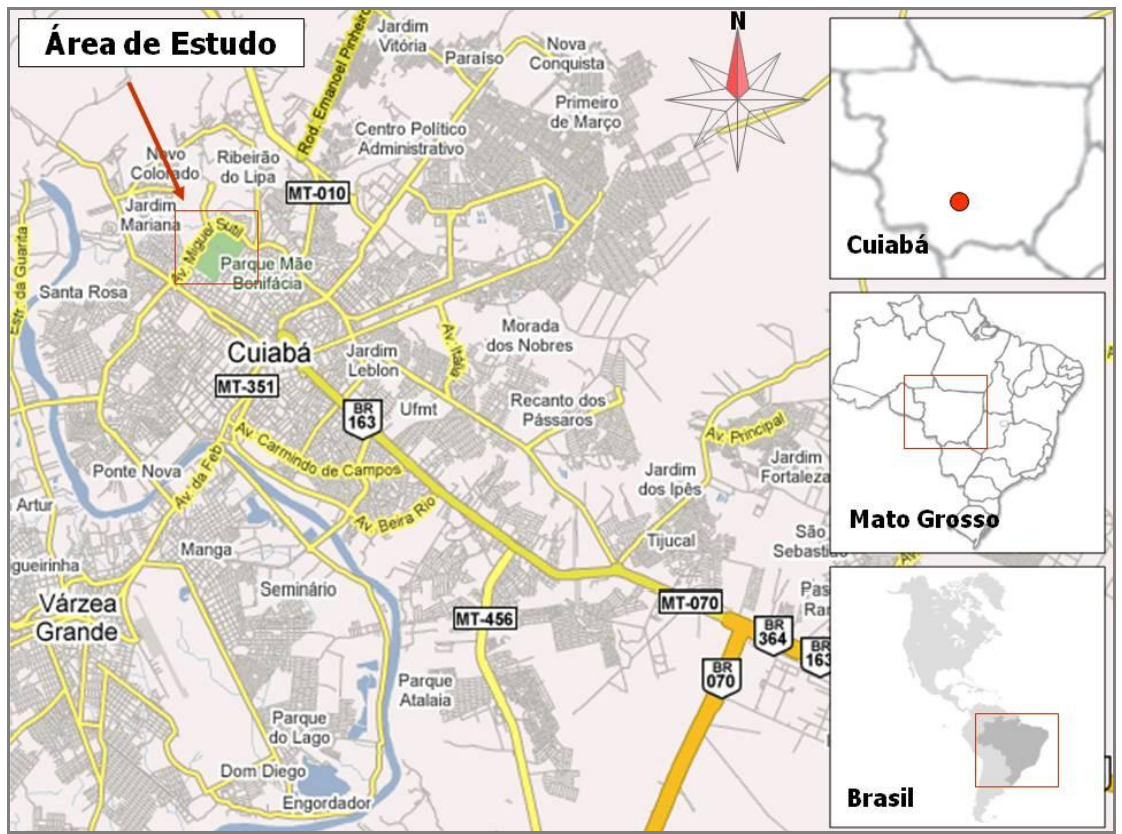

Fonte: Google Maps (2008).

Figura 1 - Localização da área de estudo

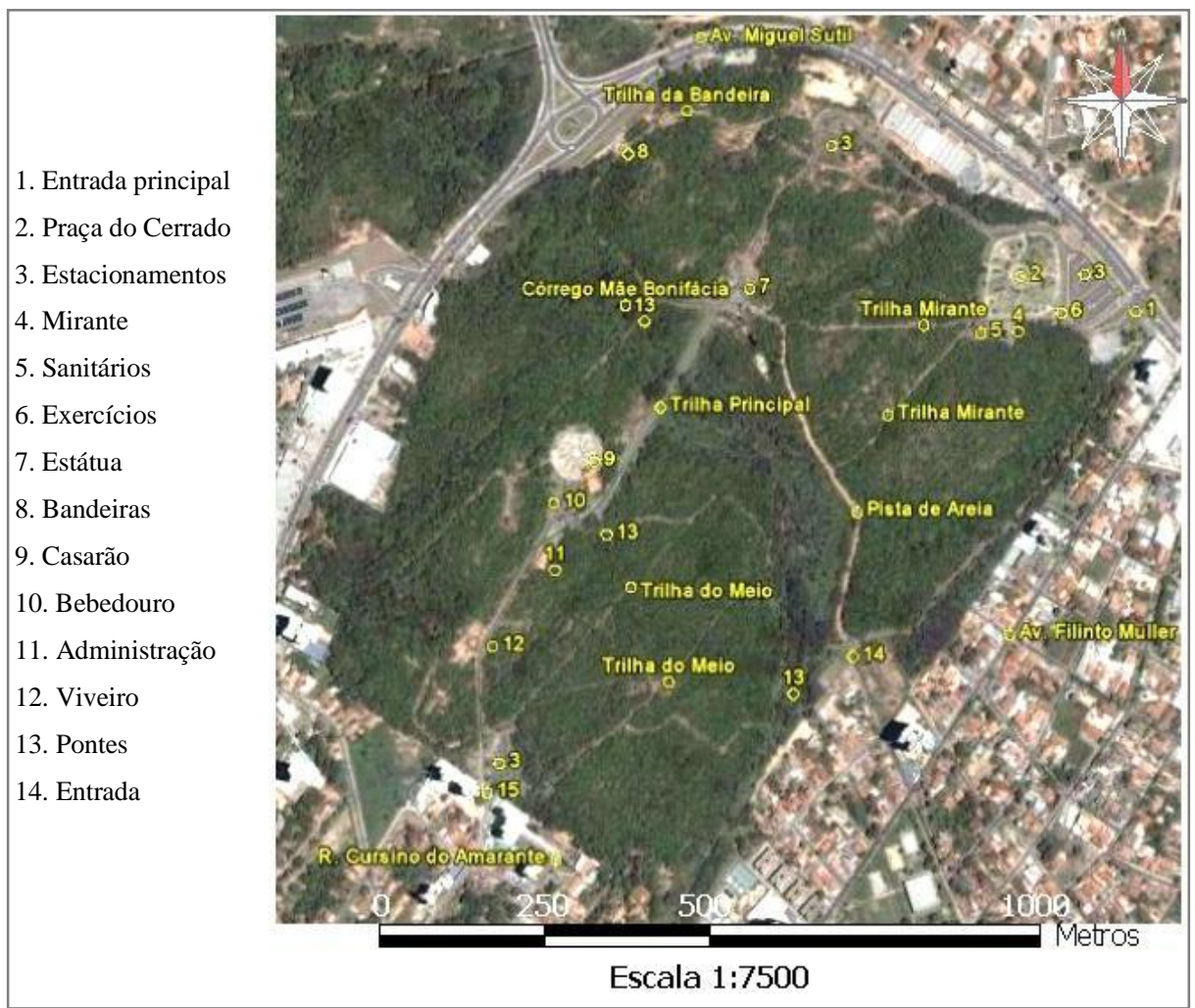

Fonte: Google Earth (2008).

Figura 2 - Infraestrutura do Parque

Cortado pelos córregos Mãe Bonifácia e Caixão, que formam uma grande área de alagamento em sua porção central, o Parque tem infraestrutura constituída por cinco trilhas principais, pontos de convívio como a Praça do Cerrado, a Praça Cívica - para a realização de eventos - e o Casarão da Administração (Figura 2). Existem dois grandes estacionamentos para automóveis e bicicletas nas duas entradas principais e outros dois estacionamentos internos, um no Casarão e outro no início da Trilha Principal. 


\section{Estudo microclimático}

Para a realização da avaliação da influência dos diferentes usos do solo e o efeito climático no ambiente urbano, elegeram-se oito pontos dentro da área delimitada para o estudo, a partir de uma combinação de dados da base cartográfica, foto aérea e visitas ao Parque. Esses pontos, denominados neste trabalho de Postos de Coleta de Medidas Móveis, caracterizam regiões com diferentes configurações de uso e ocupação do solo (Figura 3).

Em função da dinâmica própria do Sistema Clima Urbano (SCU), a pesquisa de campo foi estabelecida de forma a seguir as orientações do roteiro metodológico de Monteiro (2003), que propõe coletas de dados nas duas estações, inverno e verão, no caso, os períodos chuvoso e seco.

A abordagem global do sistema partiu da caracterização de cada microclima mediante medições móveis da temperatura do ar distribuídas pela área de estudo. As coletas das temperaturas nos ambientes internos do Parque foram realizadas por meio de caminhadas ao longo das trilhas, com um registrador digital dessa variável afastado a uma altura de $1,5 \mathrm{~m}$ do solo, devidamente calibrado e protegido da radiação solar direta por um abrigo térmico.

Na Praça do Cerrado, entrada principal do Parque, foi instalado um posto de controle (PC) com um medidor de estresse térmico digital portátil com data-logger e termômetro de globo do fabricante Instrutherm, modelo TGD - 300, devidamente sincronizado ao registrador digital móvel.

As medições iniciaram-se em 3 de novembro de 2007, estendendo-se até 26 de outubro de 2008, realizadas em dias característicos das duas estações climáticas, num total de 10 dias em cada estação. O período escolhido para as medições dos dados climáticos foi das $8 \mathrm{~h} 00$ até as 9h00, quando se concentra o maior fluxo de visitantes pelas trilhas do Parque.

Como o intervalo de tempo entre a primeira e a última medida pode ser significativo para as variações de temperatura encontradas, os dados das medidas móveis foram corrigidos para o horário inicial das medições (8h00). Para essa correção do tempo tardio foram utilizadas como referência as medições do posto de controle, com ajuste realizado a partir de equações lineares ou quadráticas, de acordo com o horário da medição e a evolução das temperaturas registradas.

\section{Estudo dos riscos da exposição ao calor na praça do cerrado}

A estação fixa no posto de controle também possibilitou o estudo dos níveis de estresse térmico a que estão submetidos os organismos das pessoas que fazem uso daquele espaço, mediante a determinação do índice de bulbo úmido temperatura de globo (IBUTG, WBGT) para o horário da medição.

O IBUTG, apesar de estabelecido em 1957, é até hoje utilizado para a determinação do risco térmico de um ambiente devido à simplicidade de sua obtenção. Os valores da temperatura equivalente do IBUTG são fixados em função do metabolismo e da aclimatação, considerando pessoas em boa saúde e com vestimentas comuns para a atividade (MONTEIRO; ALUCCI, 2007).

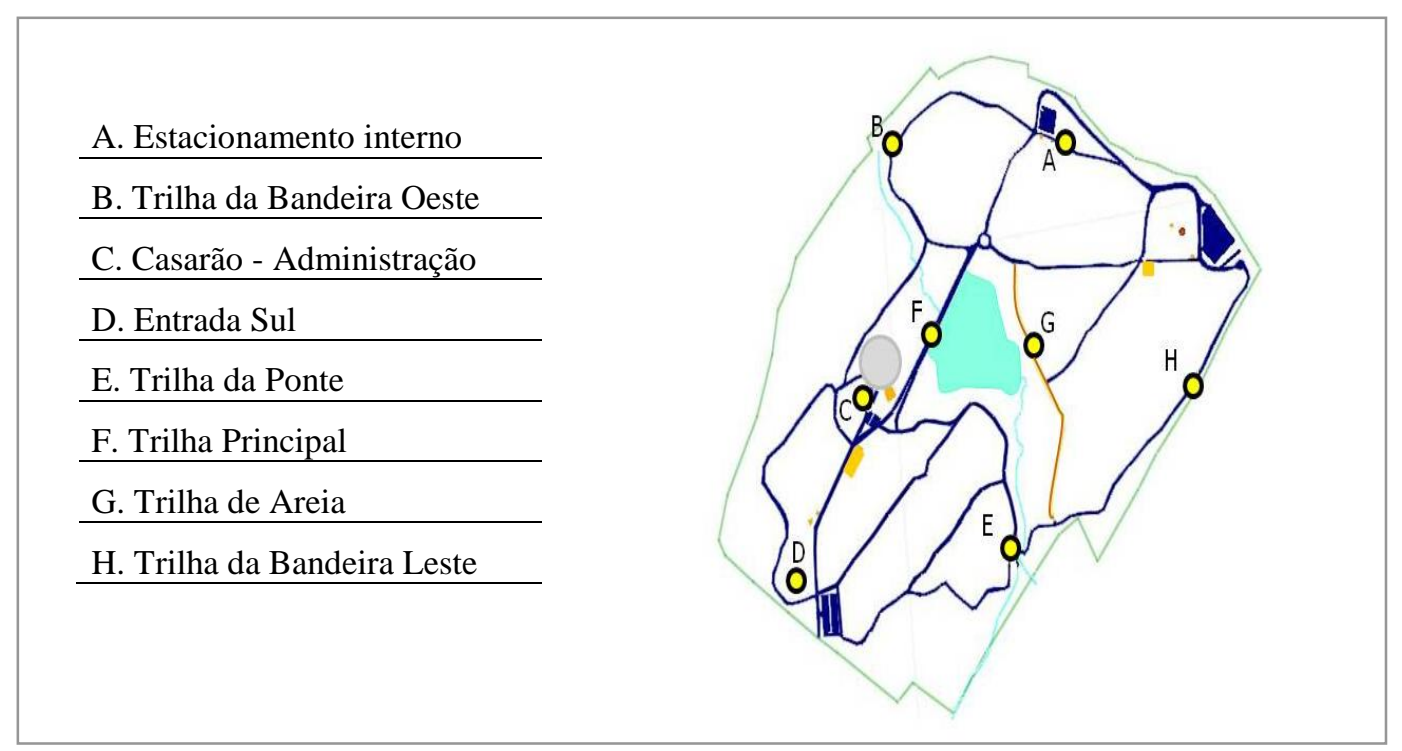

Figura 3 - Postos de Coleta de Medidas Móveis 
O índice IBUTG pode ser calculado de acordo com as seguintes equações:

(a) para ambientes internos ou externos sem radiação direta do sol:

IBUTG $=0,7 \cdot \mathrm{T}_{\mathrm{bu}}+0,3 \cdot \mathrm{T}_{\mathrm{g}}$

Eq. 1

(b) para ambientes externos com radiação solar direta:

IBUTG $=0,7 \cdot \mathrm{T}_{\mathrm{bu}}+0,2 \cdot \mathrm{T}_{\mathrm{g}}+0,1 \cdot \mathrm{T}_{\mathrm{a}}$

Onde:

$\mathrm{T}_{\mathrm{bu}}$ : temperatura do bulbo úmido ventilado naturalmente ${ }^{1}$

$\mathrm{T}_{\mathrm{g}}$ : temperatura de globo; ${ }^{2}$

$\mathrm{T}_{\mathrm{a}}$ : temperatura do ar.

A norma internacional ISO 7243 (ISO, 1989) e a nacional NR-15 (BRASIL, 1978) adotam o IBUTG para a avaliação das condições de trabalho em ambientes sob temperaturas elevadas. VimieiroGomes e Rodrigues (2001) observaram uma correlação positiva entre a taxa de sudorese e o IBUTG e entre a taxa de sudorese e o custo calórico de sessões de treinamento em ambientes quentes.

A sudorese é o principal mecanismo dissipador de calor durante atividades em ambientes quentes, representando um importante fator para uma série de distúrbios relacionados com o calor. Assim, o IBUTG é um índice que pode orientar a prevenção das complicações ocasionadas pelo estresse térmico durante exercícios físicos em ambientes quentes (POWERS; HOWLEY, 2000).

A avaliação da exposição ao calor a que estiveram submetidos, ao longo de suas atividades, os funcionários da manutenção do Parque foi realizada segundo a NR-15 (BRASIL, 1978). Essa norma para avaliação das condições de trabalho em ambientes quentes também foi utilizada neste trabalho para avaliar o estresse térmico dos visitantes do Parque em função das atividades físicas realizadas por eles, de caminhadas leves ou de atividades físicas intensas.

A Norma Regulamentadora NR-15 (BRASIL, 1978) preconiza que a taxa limítrofe para a exposição ao calor está diretamente ligada à taxa metabólica do organismo dos indivíduos. Assim, de acordo com essa norma, a atividade dos funcionários da manutenção do Parque foi

\footnotetext{
${ }^{1}$ Temperatura fornecida por um termômetro comum com o bulbo revestido por um tecido fino umedecido com água destilada. $O$ valor é um indicador do estado de umidificação da atmosfera adjacente, sendo tanto maior quanto mais úmido estiver o ar.

${ }^{2}$ Temperatura que juntamente com a temperatura e a velocidade do ar permite o cálculo da temperatura radiante média, variável que fornece indícios dos efeitos da radiação térmica sobre o indivíduo.
}

classificada, para critérios desta análise, como atividade pesada, considerando que, entre outras funções, estão operações manuais com enxadas e cortadores de grama.

A estimativa da carga térmica interna do organismo de indivíduos que praticam exercícios físicos no Parque foi realizada de acordo com o estabelecido na Tabela 1 da ISO 7243 (ISO, 1989). Esse valor estimado foi comparado a níveis de taxas metabólicas dispendidas em atividades desenvolvidas por trabalhadores, como levantar, arrastar ou empurrar pesos, segundo a NR-15 (BRASIL, 1978).

Dessa forma, de acordo com a Norma ISO 7243 (ISO, 1989), a potência metabólica da atividade de caminhada é comparável a atividades designadas de atividade leve pela NR-15 (BRASIL, 1978), enquanto uma atividade física intensa, como uma corrida com velocidade entre $5,5 \mathrm{~km} / \mathrm{h}$ e $7 \mathrm{~km} / \mathrm{h}$, se compara a atividades designadas de atividade moderada.

A análise dos riscos da exposição ao calor na Praça do Cerrado utilizou o valor médio do IBUTG, em cada estação, para avaliar a tolerância dos usuários do espaço em suas variadas atividades físicas e organizar uma alternância de tempos, entre essas atividades e repouso, conforme Tabela 1.

Valores elevados do IBUTG indicam potenciais riscos em caso de exposição contínua e a necessidade de aprofundar a análise sobre a situação.

\section{Resultados}

\section{Análise microclimática na área de estudo}

Para o tratamento dos dados climáticos foi estabelecido para este trabalho um índice, denominado de índice térmico (IT), o qual expressa a variação da temperatura do ar ao longo das trilhas relativamente ao posto de controle. Apesar de também registrar a umidade relativa do ar em todos os postos, os dados relativos à umidade relativa do ar serviram somente para embasar a análise e a discussão dos resultados dos registros de temperatura.

Os resultados da análise do ambiente térmico do Parque refletem que o ambiente construído apresentou um máximo de elevação de temperatura de $3,2{ }^{\circ} \mathrm{C}$, enquanto as áreas densamente vegetadas apresentaram um arrefecimento máximo da ordem de $3,0^{\circ} \mathrm{C}$, relativo ao posto de controle na estação chuvosa. $\mathrm{Na}$ estação seca, a elevação máxima foi da ordem de $2,2^{\circ} \mathrm{C}$, enquanto o microclima mais fresco do Parque apresentou uma diferença máxima de 2,8 ${ }^{\circ} \mathrm{C}$ em relação ao posto de controle (Figura 4). 


\begin{tabular}{|c|c|c|c|}
\hline \multirow{2}{*}{$\begin{array}{l}\text { Regime de trabalho } \\
\text { intermitente (por hora) }\end{array}$} & \multicolumn{3}{|c|}{ Tipo de atividade } \\
\hline & Leve & Moderada & Pesada \\
\hline Trabalho contínuo & até 30,0 & até 26,7 & até 25,0 \\
\hline $\begin{array}{l}45 \text { minutos de trabalho } \\
15 \text { minutos descanso }\end{array}$ & 30,1 a 30,6 & 26,8 a 28,0 & 25,1 a 25,9 \\
\hline $\begin{array}{l}30 \text { minutos de trabalho } \\
30 \text { minutos descanso }\end{array}$ & 30,7 a 31,4 & 28,1 a 29,4 & 26,0 a 27,9 \\
\hline $\begin{array}{l}15 \text { minutos de trabalho } \\
45 \text { minutos descanso }\end{array}$ & 31,5 a 32,2 & 29,5 a 31,1 & 28,0 a 30,0 \\
\hline $\begin{array}{l}\text { Trabalho não permitido sem } \\
\text { medidas de controle adotadas }\end{array}$ & acima de 32,2 & acima de 31,1 & acima de 30,0 \\
\hline
\end{tabular}

Fonte: NR-15 (BRASIL, 1978).

Tabela 1 - Valores de referência para o índice IBUTG $\left({ }^{\circ} \mathrm{C}\right)$, em função da atividade e do ciclo trabalho/descanso

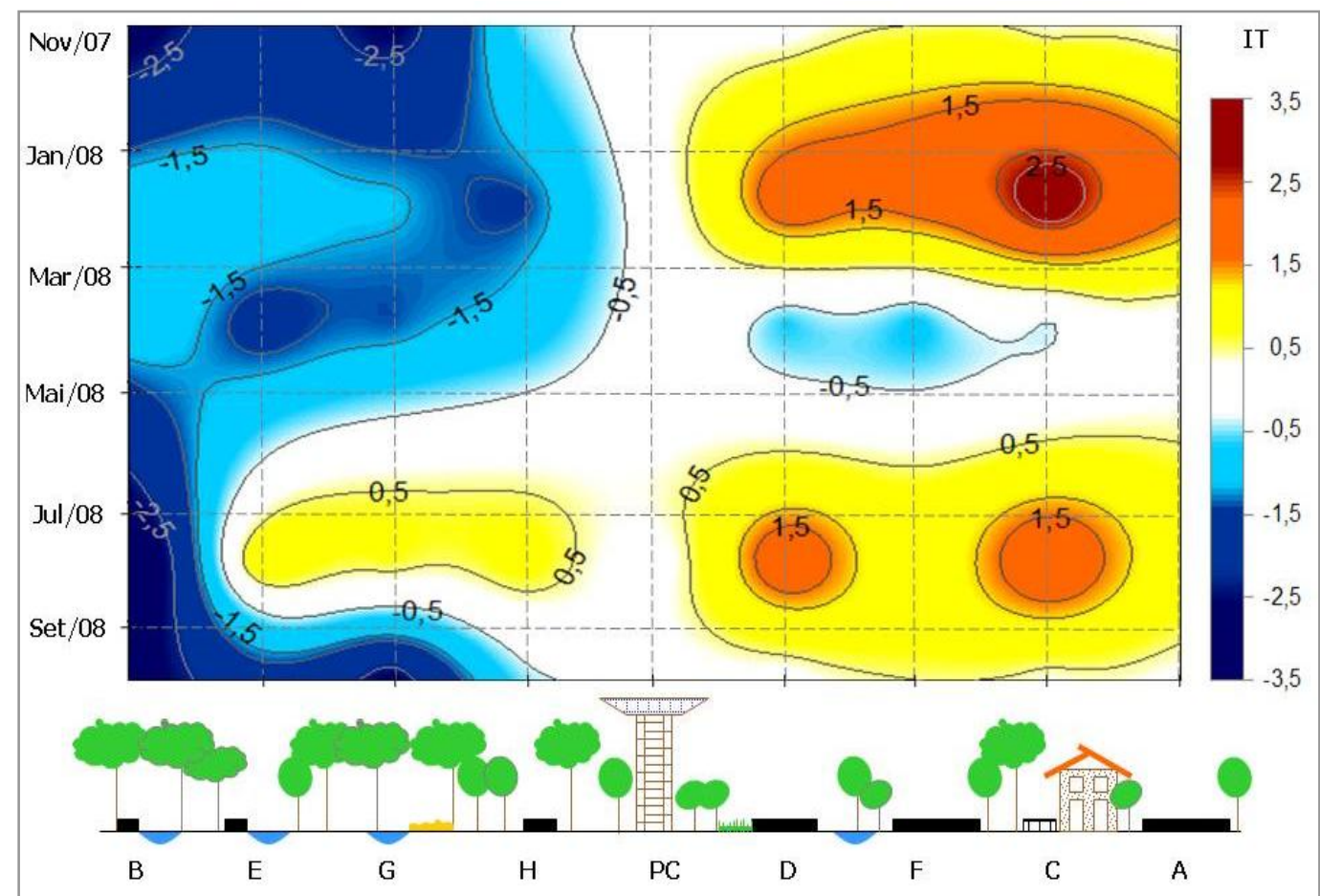

Figura 4 - Variação média da temperatura do $\operatorname{ar}\left({ }^{\circ} \mathrm{C}\right)$ em pontos internos do Parque relativamente ao posto de controle ao longo de 1 ano

Para um melhor entendimento dos resultados obtidos, realizou-se uma análise de agrupamento em função do comportamento térmico, que permitiu classificar os pontos em dois grupos, diferenciados pela densidade construída de seus entornos, confirmando a forte correlação entre esse fator e a temperatura do ar.

A análise individual dos diferentes ambientes indicou a região do Casarão da Administração (C), na porção central do Parque, como o ponto mais aquecido do lugar, com elevações de temperatura da ordem de $3,2^{\circ} \mathrm{C}$, na estação chuvosa, e de 2,2 ${ }^{\circ} \mathrm{C}$, na estação seca. De maneira semelhante, os estacionamentos, interno e da Entrada Sul, e a Trilha Principal (A, D e F) apresentaram temperaturas superiores ao controle em quase todo o ano. No entanto, no início do período seco, esses pontos apresentaram certa neutralidade térmica, além de uma tendência a arrefecimento no Posto F.

A Trilha da Bandeira Oeste (B) mostrou-se como o microclima da área de estudo de temperaturas mais amenas, apresentando temperaturas em média $2{ }^{\circ} \mathrm{C}$ 
menores que as registradas no controle para ambas as estações. Com características próximas às do Posto B, as Trilhas da Ponte, de Areia e da Bandeira Leste (E, G e $\mathrm{H}$ ) possuíam ambientes climáticos muito parecidos, que resultaram em atenuações de temperatura variando de $0,5^{\circ} \mathrm{C}$ a 1 ${ }^{\circ} \mathrm{C}$ na maior parte do ano. No auge da estação seca, entre os meses de junho a setembro, os pontos $\mathrm{E}$, $\mathrm{G}$ e $\mathrm{H}$ apresentaram uma tendência de temperatura ligeiramente superior às registradas no controle.

$\mathrm{Na}$ estação chuvosa, as médias de temperatura e umidade relativa do ar para o horário das medições foram de $30,6^{\circ} \mathrm{C}$ e $74,7 \%$, e, na estação seca, os valores encontrados foram $33,1^{\circ} \mathrm{C}$ e $58,2 \%$, tendo sido registrados, ao final das medições nesta estação, valores de umidade relativa do ar próximos a $33 \%$. Os resultados reforçam o impacto do clima da região sobre os microespaços do lugar, em especial na estação seca.

\section{Análise dos níveis de estresse térmico na praça do cerrado}

A análise para avaliar as condições de estresse provocadas pelo ambiente térmico do lugar sobre seus usuários em função da atividade desenvolvida foi realizada de acordo com o Quadro 1 da NR-15 (BRASIL, 1978), apresentado na Tabela 1.

As medições da estação fixa na Praça do Cerrado (posto de controle), realizadas em dias característicos das duas estações, encontaram valores médios do IBUTG de $28,4{ }^{\circ} \mathrm{C}$ para a estação chuvosa e de $32,1{ }^{\circ} \mathrm{C}$ para a estação seca, no período das $8 \mathrm{~h} 00$ às $9 \mathrm{~h} 00$.

Para se analisar a possibilidade de ocorrência de estresse térmico em função da atividade realizada, relacionaram-se os valores do IBUTG com a taxa metabólica ou gasto energético, conforme preconiza a NR-15 (BRASIL, 1978).

Dessa forma, tem-se que, para a estação chuvosa, a potência metabólica da atividade de caminhada, comparável a atividades designadas como atividade leve, no que diz respeito às faixas limítrofes para a exposição ao calor, não oferece riscos maiores ao estado geral de saúde dos indivíduos que venham a praticá-la no período da manhã na área de estudo. Para praticantes de atividades físicas de maior impacto, com potência metabólica comparada a atividades designadas como atividade moderada, o resultado desta análise sugere que a prática desse tipo de atividade no lugar deva ser realizada por um período máximo de $30 \mathrm{~min} / \mathrm{h}$ associado a $30 \mathrm{~min} / \mathrm{h}$ de descanso no próprio local.

Pela NR-15 (BRASIL, 1978), a atividade dos funcionários da manutenção do Parque, classificada para critérios desta análise como atividade pesada, deve seguir um regime de trabalho na estação chuvosa de $15 \mathrm{~min} / \mathrm{h}$ com 45 $\mathrm{min} / \mathrm{h}$ de descanso no próprio local de trabalho.

Pela avaliação do ambiente térmico para a estação seca, no que diz respeito às faixas limítrofes para a exposição ao calor, não deve ser permitido o trabalho dos funcionários da manutenção do Parque sem precauções especiais nessas condições, $\mathrm{e}$, da mesma forma, atividades físicas intensas também devem ser evitadas. Atividades de caminhada nesse período, tomando medidas adequadas de proteção, devem respeitar um tempo máximo de $15 \mathrm{~min} / \mathrm{h}$ com $45 \mathrm{~min} / \mathrm{h}$ de descanso.

Na estação seca, a avaliação segundo as diretrizes estabelecidas pela NR-15 (BRASIL, 1978) sugere que um indivíduo em atividade física nesse lugar durante o período das medições encontra-se submetido a elevado risco de seu estado geral de saúde.

\section{Discussão}

O estudo microclimático realizado na área do Parque confirmou a evidência de que existe uma relação direta entre os padrões de ocupação do solo e a topografia sobre o ambiente térmico do lugar. Verificou-se que os diferentes microclimas do Parque são influenciados, por um lado, pela mata, pela proximidade a corpos d'água, pela presença de superfícies gramadas, e, por outro lado, pela superfície e largura dos pavimentos das trilhas, pelas construções do Parque e pela barreira de edifícios altos que se forma nos limites dele.

A região da Trilha da Bandeira Oeste (B) apresentou-se como uma ilha de frescor para o lugar. Acredita-se que a largura da via e a altura das árvores, cujas copas se entrelaçam, formando um dossel contínuo sobre a via, minimizam a entrada de radiação solar nesse ambiente, contribuindo para as melhores condições climáticas desse microespaço. Outro fator que reforça essa característica é o fato de a Trilha estar posicionada no fundo do vale e ser cortada pelo córrego Mãe Bonifácia, situação em que a umidade proveniente deste e o ar frio que escoa pela encosta no início da manhã são responsáveis pelas características microclimáticas do lugar.

A Trilha da Ponte (E), situada no lado leste do Parque, devido à largura da via, apresenta menor visão do céu, que, associada à presença de árvores de alto porte, produziu nesse posto um microclima com uma atenuação na temperatura do ar de até $2^{\circ} \mathrm{C}$ em relação ao controle na estação chuvosa. A Trilha de Areia $(\mathrm{G})$, que segue o contorno da área alagada, tem características semelhantes às do 
Posto E. Apresentando uma boa conformação, estreita e com presença de árvores altas por toda sua extensão, apresentou uma atenuação na temperatura do ar durante quase todo o período de medições. Nesses espaços a forma como é permitida a entrada da luz solar no ambiente representou um aspecto diferenciador de cada microclima.

O estudo confirma a hipótese de Corbella (2003) de que a proteção da radiação solar é um requisito indispensável a um projeto para regiões localizadas em latitudes com abundância de luz natural. Desse cuidado irá decorrer a qualidade ambiental e a valorização do espaço.

A Trilha da Bandeira Leste $(\mathrm{H})$ teve suas temperaturas na maior parte das medições em neutralidade com o controle, fornecendo indícios de que, apesar da formatação de largura estreita da via e a presença de árvores restringindo a entrada de radiação solar em sua base, a proximidade dos edifícios localizados na avenida vizinha ao Parque anulou os possíveis efeitos de arrefecimento.

Nas regiões do Casarão da Administração (C) e da Entrada Sul (D), o ambiente térmico foi deteriorado pela associação dos fatores topográficos e de ocupação do solo. Devido à existência de grandes extensões de pavimento asfáltico com um paisagismo formado por uma baixa densidade de árvores de médio porte, é permitido o livre acesso da radiação solar ao solo. A orientação desses espaços, situados na vertente sul da bacia do Córrego Mãe Bonifácia, também favorece muito a incidência da radiação solar na maior parte do ano.

No estacionamento interno (A), mesmo situado na vertente norte, o padrão do uso do solo, ou seja, o grande espaço asfaltado e a presença de uma pequena faixa de vegetação rasteira contribuíram para o maior aquecimento do ar. Esse posto apresentou temperaturas acima das registradas no posto de controle durante quase todo o período de medições.

Compreendendo o fundo do vale do Córrego Mãe Bonifácia, a região que envolve a Trilha Principal (F) tem um padrão de arruamento com pista dupla, o que permite o livre acesso da radiação solar a sua base. Para a construção dessa via, uma grande quantidade de árvores do entorno próximo foram substituídas por um extenso gramado. Dessa forma, os resultados sugerem que o possível efeito de arrefecimento do ar, pela presença da região alagada nas proximidades da Trilha, foi anulado pela forma de ocupação do solo.

$\mathrm{Na}$ estação seca, o ambiente térmico do lugar fica bastante prejudicado. As regiões dos Postos E, G e $\mathrm{H}$, por exemplo, apresentaram uma inversão nos padrões da temperatura do ar, de arrefecimento para aquecimento, em relação ao posto de controle. No auge da estação, as temperaturas nestes postos suplantaram em $0,5^{\circ} \mathrm{C}$ as registradas na Praça do Cerrado.

A ausência de precipitações associada às características da vegetação predominante nos terrenos mais elevados da área, o cerrado stricto sensu, com árvores decíduas que apresentam perda parcial de folhas na estação seca (Figura 5), podem explicar a inversão dos padrões da temperatura do ar nessa época do ano.

A Praça do Cerrado (PC), onde se realizou a análise de estresse térmico, encontra-se próxima a uma avenida com grande circulação de veículos, separada desta por um estacionamento de pavimento asfáltico. Muito exposta à radiação solar durante todo o dia, a intervenção do projeto nesse espaço produziu um ambiente muito impermeabilizado, com algumas árvores exóticas de médio porte em meio a uma área equivalente gramada.

Assim, os elevados valores do IBUTG encontrados nesta análise refletem, além dos rigores climáticos da região, as características morfológicas do lugar onde aconteceu a análise de estresse térmico. Diante de todas essas observações, pode-se averiguar possíveis impactos à saúde dos usuários desse espaço devido à exposição ao calor.

O índice IBUTG apresentou um resultado satisfatório nas condições da estação chuvosa para as atividades físicas realizadas no lugar ao longo do horário do estudo. $\mathrm{Na}$ estação seca, as condições térmicas da Praça do Cerrado foram consideradas muito desfavoráveis para a realização de qualquer atividade física. Nessa época, a cidade de Cuiabá registra índices de umidade relativa do ar inferiores a $30 \%$, quando a escala de referência para o nível de umidade, produzida pela Organização Mundial da Saúde, indica estado de alerta para registros e estado de emergência para números abaixo de $12 \%$. A Defesa Civil do estado, na estação de seca, alerta a população sobre os riscos à saúde que a baixa umidade do ar pode causar, de forma que as atividades físicas devem ser realizadas com cautela e nunca entre as $10 \mathrm{~h} \mathrm{e}$ as $16 \mathrm{~h}$. 

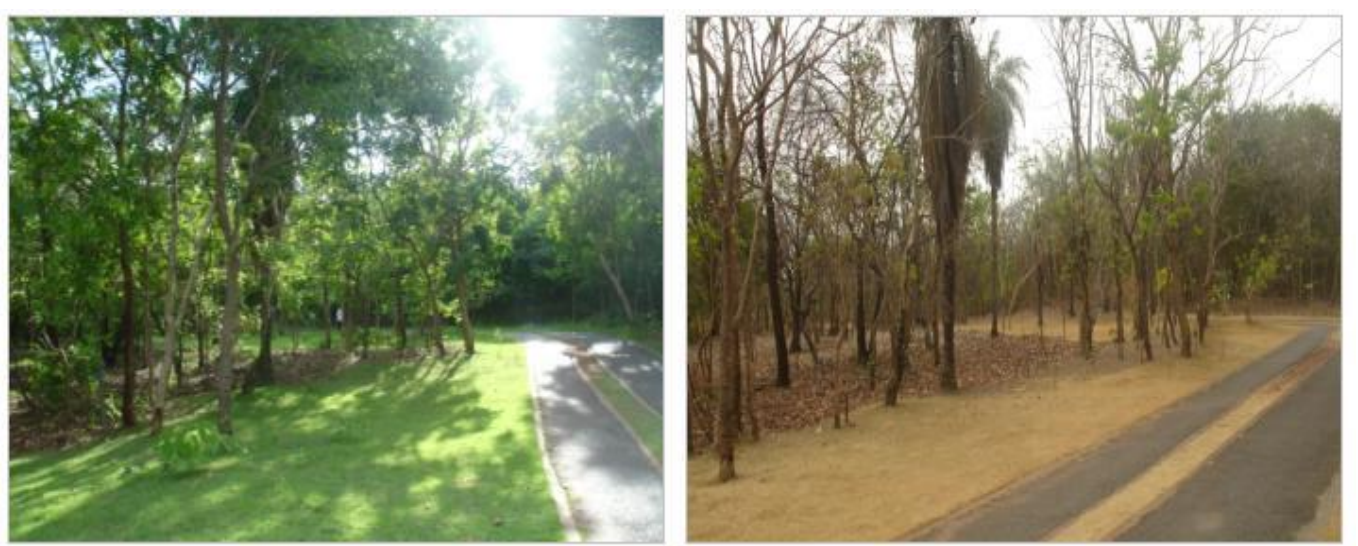

Figura 5 - Trilha da Bandeira Leste $(\mathrm{H})$ nas estações chuvosa e seca respectivamente

Atividades físicas nessas condições podem ocasionar perdas hídricas pela sudorese, que, se não repostas adequadamente, podem levar à desidratação. Por outro lado, a taxa de sudorese é função do IBUTG do ambiente e do custo calórico das sessões de treinamento (COELHO et al., 2008). Assim, a potência metabólica das atividades físicas desenvolvidas, combinada com as condições térmicas do ambiente onde foram realizadas, pode oferecer risco para hipertermia, constituindo-se uma situação potencialmente fatal.

A fim de evitar possíveis efeitos adversos da desidratação sobre os organismos dos usuários de espaços expostos ao calor, é sempre recomendada a ingestão de água em quantidades suficientes para repor a perda hídrica pela sudorese. A administração do Parque instrui os funcionários para uma hidratação adequada, sugerindo a interrupção de suas atividades sempre que eles sentirem algum desconforto.

Apesar dessas recomendações informais, as condições ambientais do Parque exigem um programa mais rigoroso de medidas de controle à exposição ao calor dos trabalhadores, com a finalidade de:

(a) limitar o tempo de exposição destes ao agente físico, alterando ou limitando os horários de trabalho nos ambientes onde existe geração excessiva de calor, especialmente na estação seca;

(b) investir em equipamentos de proteção individual que reduzam a taxa metabólica do organismo dos funcionários na realização das atividades diárias;

(c) efetivar um programa de hidratação, pela reposição de água e sais minerais perdidos durante a transpiração;

(d) aclimatar, por um período de adaptação de cinco dias, empregados recém-admitidos e os que retornam após período de férias; e (e) promover a realização de exames médicos periódicos.

Campanhas educativas que alertem trabalhadores e supervisores para reconhecer alguns sinais de problemas causados pelo calor também podem trazer bons resultados, reduzindo muito os riscos gerados por esse agente físico.

\section{Conclusões}

Os resultados alcançados nesta análise sugerem a necessidade de uma reavaliação do tempo de permanência de indivíduos em atividades físicas intensas nesses ambientes. Para melhor avaliar a possibilidade de impactos à saúde, faz-se necessário executar outras análises, mais detalhadas, de estresse por calor, de acordo com métodos mais sofisticados.

Considera-se importante também a realização de estudos que ajudem a conhecer as condições ambientais que possam levar a estados de estresse térmico, mecanismos de determinação e ações de prevenção e correção que considerem fatores como características genéticas e aclimatação da população aos rigores dessas condições climáticas. Nas regiões tropicais, a sombra, a presença de vegetação e água e a brisa suave fazem com que as pessoas apresentem uma sensação de conforto, em função do valor atribuído ao espaço, que pode diferir das classificações dos métodos existentes.

O estudo pode contribuir para a compreensão das especificidades do clima local, fornecendo subsídios para políticas públicas que visem a uma melhor ambiência em áreas urbanas, seja na construção de outros parques ou na revitalização de áreas verdes em regiões urbanas com as mesmas características climáticas.

Cuiabá, outrora conhecida por "Cidade Verde" pelos extensos fragmentos de cerrado presentes em toda a área urbana, vem sofrendo uma acelerada 
atividade imobiliária sem garantias de preservação das áreas verdes, de forma que outros estudos na área do conforto térmico, especialmente em projetos de espaços públicos abertos, podem trazer significativas contribuições para a cidade.

Escolhida como uma das sedes da Copa do Mundo de 2014, a cidade deve repensar suas construções para o evento internacional que se aproxima, de forma a oferecer para os visitantes e população, já não tão aclimatada às atuais condições, espaços com as características de seu clima, quente, porém agradável.

\section{Referências}

BRASIL. Ministério do Trabalho. NR-15: atividades e operações insalubres. Brasília, DF, 1978.

COELHO, L. G. et al. A Radiação Solar Aumenta o Estresse Fisiológico Durante Exercício sob o Sol quando Comparado com Exercício em Câmara Ambiental com Mesma Temperatura Seca e Umidade Relativa do Ar. Motriz, Rio Claro, v. 14. p. S80-S81, 2008.

CORBELlA, O. Em Busca de uma Arquitetura Sustentável para os Trópicos: conforto ambiental. Rio de Janeiro: Revan, 2003.

GOOGLE. Google earth. 2008.

GOOGLE. Google maps. 2008.

INTERNATIONAL ORGANIZATION STANDARDIZATION (ISO). ISO 7243: hot environments: estimation of the heat stress on working man. Geneva, 1989.

LACAZ, C. S. Meteorologia Médica. In: Lacaz, C. S.; Baruzzi R. G.; Siqueira Júnior W. Introdução à Geografia Médica do Brasil. São Paulo: Edgard Blücher: Edusp, 1972.

\section{LAMBERTS, R.; XAVIER, A. A. P. Conforto}

Térmico e Stress Térmico. Florianópolis: Laboratório de Eficiência Energética em Edificações, Universidade Federal de Santa Catarina, 2002. Disponível em: <http://www.labeee.ufsc.br/arquivos>. Acesso em: 12 dez. 2008.

MATSUDO, V. K. R. et al. Usando a Gestão Móbile de Modelo Ecológico para Promover Atividade Física. Diagnóstico \& Tratamento, São Paulo, v. 11, n. 3, p. 184-189, jul./set. 2006.

MONTEIRO, C. A. F. Teoria e Clima Urbano. In: MONTEIRO C. A. F.; MENDONÇA F. (Org.).

Clima Urbano. São Paulo: Contexto, 2003.

MONTEIRO, L. M.; ALUCCI, M. P. Questões Teóricas de Conforto Térmico em Espaços Abertos: consideração histórica, discussão do estado da arte e proposição de classificação de modelos. Ambiente Construído, Porto Alegre, v. 7, n. 3, p. 43-58, 2007.

POWERS, S. K.; HOWLEY, E. T. Exercise Physiology: theory and application to fitness and performance. Boston: McGrall Hill, 2000.

ROMA, K. Caminhar é a atividade física preferida dos cuiabanos. Diário de Cuiabá, Cuiabá, 08 abr. 2008. Disponível em:

<http://www.diariodecuiaba.com.br>. Acesso em: 15 nov. 2008.

VIMIEIRO-GOMES, A. C.; RODRIGUES, L. O. C. Avaliação do Estado de Hidratação dos Atletas. Revista Paulista de Educação Física, São Paulo, v. 15, n. 2, p. 201-211, jul./dez. 2001.

WORLD HEALTH ORGANIZATION (WHO). Global Strategy on Diet, Physical Activity and Health. Geneva, 2006. Disponível em: <http://www.who.int/dietphysicalactivity/strategy/ eb11344/strategy_english_web.pdf>. Acesso em: 05 mar. 2009.

\section{Agradecimentos}

À Fundação de Amparo à Pesquisa do Estado de Mato Grosso (Fapemat), pelo suporte financeiro. 